\title{
A Escola de Medicina da Bahia ou o lugar onde Pedro Archanjo foi bedel: representações de estereótipos acerca de macumba, loucura e crime
}

\author{
DOI: 10.3395/reciis.v4i3.401pt
}

\section{Ana Cristina de Souza Mandarino}

Bolsista de Desenvolvimento Científico Regional do CNPq - Nível B no Programa de Pós-Graduação em Antropologia, Universidade Federal da Bahia - UFBA, Doutora em Comunicação e Cultura pela Universidade Federal do Rio de Janeiro -UFRJ e Professora Associada do Programa de Pós-Graduação em Ciências da Saúde da Universidade Federal de Sergipe - UFS. Co-organizadora das coletâneas "Leituras de Novas Tecnologias e Saúde, Leituras Afro-Brasileiras: territórios, religiosidades e saúdes" e "Racismos: olhares plurais", editada pela Editora UFBA e Autora do Livro "(Não) deu na primeira página: macumba, loucura e criminalidade", editada pela Editora UFS. anamandarino@gmaill.com

\section{Estélio Gomberg}

Pós-Doutorando em Ciências Sociais (bolsista Fapesb PósDoc I), Doutor em Saúde Pública e Pesquisador Associado do Laboratório de Desigualdades Sociais/Programa de Pós-Graduação em Ciências Sociais, Universidade Federal da Bahia/UFBA e Co-organizador das coletâneas "Leituras de Novas Tecnologias e Saúde, Leituras Afro-Brasileiras: territórios, religiosidades e saúdes" e "Racismos: olhares plurais", editada pela Editora UFBA. estelio68@gmail.com

\begin{abstract}
Resumo
O presente artigo objetiva discutir, através da ideologia vigente entre os integrantes da Escola de Medicina da Bahia, como estes vão tratar a questão da loucura e da criminalidade frente aos novos paradigmas científicos do Século XIX e de como estes vão ser responsáveis pela concepção dos estereótipos que vão incindir sobre negros, mestiços e adeptos das religiões afrobrasileiras. Também analisaremos, através daquela que se tornou a publicação científica mais importante da época - Gazeta Médica da Bahia - , como os ideais e valores de uma classe em emergência eram difundidos com vistas à manutenção de um ideal - o fim da miscigenação.
\end{abstract}

\section{Palavras-chave}

Escola Médica da Bahia; Gazeta Médica da Bahia; esteriótipos; religiões afro-brasileiras
O papel e a relevância da prática médica no contexto das relações raciais que se estabeleceram a partir do Século XIX, assim como as teorias emergentes, vão encontrar espaço privilegiado na Escola de Medicina da Bahia através de um grupo específico de médicos, que costumavam se autodesignar como membros da Escola Nina Rodrigues. Este grupo de profissionais foi responsável pela introdução de uma discussão até então insípida no Brasil: o papel que a raça poderia desempenhar na constituição de patologias mentais e, consequentemente, na construção de estereótipos. Estes indivíduos foram responsáveis pelo estabelecimento e fundação da Medicina Legal no Brasil e pelo periódico que Ihes deu sustentação: a Gazeta Médica da Bahia.
Segundo Schwarcs (1993), a discussão sobre a higiene pública mobilizou grande parte das atenções até os anos de 1880 mas, a partir da década seguinte, será a vez da medicina legal, com a nova figura do perito - que, ao lado da polícia, explica a criminalidade e determina a loucura - e que, nos anos 30, cede lugar ao eugenista, que passa a separar a população enferma da sã.

Após a publicação e divulgação de $A$ origem das espécies, de Charles Darwin, em 1859, as discussões entre poligenistas - os que acreditavam em uma origem plural da humanidade e no escalonamento em hierarquias que levavam a diferenças raciais- e os monogenistas - os que acreditavam em uma origem única - acabam por permitir que uma doutrina de 
clara inclinação biológica acabe por se delinear como uma explicação plausível aos comportamentos humanos distintos entre si.

Entre as várias teorias que ganham espaço a partir do segundo quartel do Século XIX, uma delas em especial, a teoria da eugenia, - que significa etimologicamente eu: boa; genus: geração - ganha considerável notoriedade. Seu surgimento no cenário acadêmico se dá pela primeira vez em 1883, criada pelo geógrafo inglês Francis Galton, cujo objetivo primordial era a comprovação de que a capacidade humana tinha origem na hereditariedade e não na educação. A partir deste texto, amplamente aceito entre a comunidade científica, as proibições de relacionamentos interraciais e com pessoas classificadas como incapazes, tinha como meta intervir para um melhor "equilíbrio genético", "um aprimoramento das populações", ou a identificação precisa das "características físicas que apresentavam grupos sociais indesejáveis". (GALTON, 1979 apud SCHWARCS, 1993)

O movimento eugenista representou, portanto, a aplicação de um mecanismo controlador cujo objetivo residia em separar elementos racialmente distintos no intuito de depuração, que incluíam, em verdade, uma seleção rígida com contornos segregacionistas.

Como já assinalamos, é a partir de 1890 que a medicina legal ganha espaço nas discussões acerca da saúde da população local. Em uma arena de disputas acirradas e de predominâncias teóricas com vistas à consolidação de uma prática profissional que estava ainda em construção, a Escola de Medicina da Bahia vai buscar discutir um dos aspectos mais constantes dos debates científicos mundiais: a questão da miscigenação da raça e os desequilíbrios advindos desta mistura.

Na Bahia, os médicos concentravam-se especialmente na questão racial e no que consideravam ser os desdobramentos da constituição de um país mestiço - o problema do negro no Brasil passava a ser uma questão científica, vista pelo ângulo do evolucionismo social e da teoria da degenerescência (SCHWARCZ, 1993).

A Escola de Medicina da Bahia surge em 03 de outubro de 1832 como um desdobramento da Academia Médico Cirúrgica, fundada em 1808 com a chegada da Corte ao Brasil e associada ao Hospital Real Militar da Cidade de Salvador, sendo a primeira escola de ensino médico do país. (MAIO, 1995)

Desde 1870 podemos verificar o início de reformas profundas no tocante à institucionalização do ensino da medicina no país. Nos anos 80, podemos perceber que estas mudanças tiveram resultados diferenciados nos dois principais centros médicos do país. O Rio de Janeiro, por estar num processo de institucionalização da medicina mais avançado que o da Bahia e ser o local onde se localizava o poder central, conseguiu extrair maiores recursos do governo imperial. Na Bahia veio a ocorrer um descompasso entre as mudanças legislativas e a alocação de verbas para o sucesso das transformações propostas. (MAIO, 1995). Neste momento, A Gazeta Médica da Bahia, fundada em 1886, vai ocupar um lugar de destaque no tocante às denúncias contra o tratamento desigual exercido pelo Segundo Reinado em relação ao Estado da Bahia, ganhando a visibilidade necessária para que se transformasse nos anos posteriores na principal revista científica nacional.

As duas reformas do ensino tinham como objetivo a estruturação do campo profissional médico (1879 e 1884). Era perfeitamente compreensível a instauração, então, de periódicos - Gazeta Acadêmica e Revista Médico Legal e associações profissionais cuja função consistia em dar suporte a todo um plano de visibilidade e legitimação da prática médica. Esta dinâmica institucional buscava também separar suas atividades profissionais da atuação daqueles considerados curandeiros, charlatães e espiritualistas.

A relação de Nina Rodrigues com a Gazeta Médica da Bahia é antiga. Com a morte do médico catedrático Virgílio Damázio em 1891, e amparado pela reforma Benjamim Constant, Nina então professor substituto é transferido para a cadeira de Medicina Legal, tornando-se neste momento redator chefe da Gazeta Médica da Bahia e sendo nomeado, posteriormente, para a Congregação da Escola de Medicina. (MAIO, 1995).

Há de se entender, que, nos anos seguintes, a Gazeta Médica tenha se transformado no principal veículo difusor das teorias da degenerescência e da inferioridade racial dos grupos negros, pois aqueles que possuíam o direito de editála usavam-na como uma tribuna para levarem a público as discussões que estes achavam adequadas, fazendo da saúde, neste momento, um negócio de interesses pessoais.

A conversão definitiva de Nina Rodrigues à medicina legal data da publicação de As Raças Humanas e a Responsabilidade Penal no Brasil (1894), claramente inspirado na obra de Cesare Lombroso "L'Uomo Delinquente" de 1876, Cuja teoria aponta para a hereditariedade dos crimes cuja origem estaria na degeneração de certas raças consideradas inferiores. Criminosos seriam casos de atavismo evolutivo em nosso meio, germes de um passado ancestral que permaneceriam adormecidos em nossa hereditariedade. 
Em alguns indivíduos desafortunados, o passado tornar-se-ia presente. A identificação de "criminosos natos" poderia ser realizada através da apreciação dos seus sinais anatômicos. O atavismo presente neles seria tanto físico quanto mental, sendo os primeiros os mais importantes. Comportamentos criminosos poderiam também aparecer em homens normais, contudo a anatomia teria os instrumentos necessários para revelar o "criminoso nato", que não escapava, portanto, das características herdadas (GOULD, 1991).

Neste momento, a teoria da eugenia entra em cena. Teoria que aglutina um conjunto de idéias e práticas relativas a um "melhoramento da raça humana pela seleção dos genitores, tendo como base o estudo da hereditariedade" (MACIEL, 1999). Enquanto os médicos cariocas eram francamente inclinados para o combate das doenças, em especial as doenças tropicais, na Bahia e entre os médicos baianos era o "doente" ou a população doente que estava em questão. O combate à miscigenação é retomado com a introdução desta teoria cujo contato deveria ser evitado com a intenção de prevenir a loucura e a criminalidade, proibindo os casamentos interraciais, e também considerando doentes todos os membros frutos dessas uniões, seus descendentes e todo o seu modo vida - incluindo-se sua religião e cultura. Assim, a partir dos anos 20, estes irão promover programas "eugênicos de depuração".

O tema racial aparece distintamente em ambas as Escolas; no entanto, na Bahia, o recorte servirá como instrumento de segregação com o objetivo de conter os índices de criminalidade, loucura e a posterior degeneração.

Neste contexto a Imprensa Médica será importante difusora destas teorias junto à população. Criada por um número pequeno de profissionais, a princípio, suas publicações eram apenas destinadas à classe médica. No entanto, com o avanço dos estudos, junto com o desenrolar de experiências, cujo objetivo servia para referendar suas teorias, essas passam a ser dirigidas à população em geral, como forma de preveni-la do contágio. (MANDARINO, 2007)

Com efeito, a partir de meados do Século XIX, o jornalismo científico surge como uma nova opção para os profissionais de Medicina. Estes abandonam a imprensa cotidiana e, contando com um material específico - entre relatórios, monografias, artigos conferências e comunicações - passam a redigir suas próprias publicações. (JACOBINA et al., 2008).

Estes jornais, editados em sua maioria nos principais centros do Império, tiveram como característica a pouca duração. Diferente, no entanto, foi o caso de duas revistas: tanto a Gazeta Médica da Bahia como o Brasil Médico, do Rio de Janeiro, caracterizaram-se não só pela grande difusão fora do meio acadêmico, como pela longa duração. (SCHWARCS, 1993).

Ambas as revistas, embora possuíssem diferenças temáticas, mantinham um intercâmbio entre si e com outras publicações científicas, uma vez que a escassez de material era grande. Do Rio de Janeiro as notícias mais constantes eram aquelas que davam conta das campanhas sanitárias e do combate as doenças tropicais, enquanto da Bahia prioritariamente discutia-se os rumos da medicina legal e posteriormente dos estudos sobre alienação e doença mental.

A doença era apontada enquanto sinal da degenerescência mestiça, chegando-se à conclusão de que "a syphillis precisaria ser investigada no indivíduo e na raça" (GMB, 1894 apud SCHWARCS, 1993).

O trecho acima ilustra não só o caso particular de uma doença, como revela uma tendência geral. Raça surge como tema fundamental de vários médicos da época e em suas considerações e diagnósticos. Vários eram os artigos desta Revista que refletiam sobre o tema: "As raças e seus cheiros" (1921), "Raça e Civilização" (1880), "Raça e Degeneração" (1887), "O cruzamento racial" (1891).

Neste mesmo período, os textos de Nina Rodrigues começavam a ser publicados pela Gazeta com ênfase em um único argumento: o estabelecimento da diferença entre as raças e a condenação da mestiçagem. Utilizando-se do modelo social-darwinista, esse cientista fará uma leitura original da realidade nacional ao apontar o cruzamento como o "nosso maior mal", ao condenar a hibridação das raças e sua conseqüente degeneração. (SCHWARCS, 1993).

Maior expositor da Escola de Medicina da Bahia, primeiro como aluno e posteriormente como professor e, por último, como diretor, nas palavras de Nina Rodrigues (1988), o problema negro se desmembrava em múltiplas feições:

uma do passado - negros africanos que colonizaram o país; outra do presente - negros, baianos, crioulos e mestiços; a última, do futuro - mestiços e brancos crioulos. Questão do passado, do presente e do futuro, a mestiçagem preocupava os intelectuais baianos devido à novidade que ela significava: "a insegurança de seus diagnósticos [...] as dificuldades nas avaliações scientífica dessas populações (GMB, 1901 apud SCHWARCS, 1993)

A partir do início do Século XIX, já era possível identificar artigos sobre medicina legal. Neles, o objeto privilegiado não é mais a doença ou o crime, mas o criminoso. Abandona-se o vocabulário médico, para se introduzir um linguajar que mais se aproxima do discurso policial e do direito. 
Se desde 1839 existiam artigos e dissertações sobre tal tema, a partir dos anos 80 elas se multiplicarão, passando de 21 para 100 até 1915. A análise do perfil do criminoso foi o tema privilegiado, que, seguindo os argumentos e orientações da escola italiana de Lombroso, analisaram com insistência a correlação entre "criminalidade e degeneração". (SCHWARCS, 1993)

Era na condição de médicos peritos, especializados no estudo da mente do criminoso, que esses profissionais defenderão a criação de uma prática diversa. Afinal, estava em jogo a supremacia e autonomia no reconhecimento do crime e na qualificação do criminoso.

À frente desses movimentos, sobressaía a figura de Nina Rodrigues, professor da escola e grande defensor radical da medicina legal e de sua necessária autonomia. É a partir de sua atuação que se consolida um processo de afirmação profissional, cujo propósito ia além da mera defesa da medicina legal. O que, na verdade, encontrava-se em jogo, conforme podemos perceber, era a criação de uma identidade de grupo, bem como a imagem social dos médicos, cuja prática, em seu início, havia sido tão desprezada.

Neste caminho, foi fundamental o apoio da Gazeta Médica da Bahia que, abrindo espaço para Nina Rodrigues e seus discípulos, vai contribuir decisivamente através da veiculação de tais teorias, para a cristalização do preconceito sobre os negros.

Chamada por Mariza Corrêa (1983), de "a ilusão da liberdade", essa percepção própria da escola baiana será ainda mais aprofundada a partir dos anos 20, com "os estudos de alienação" e de "medicina mental". "A revista seguia de perto os passos de Nina Rodrigues, cuja atenção neste momento também havia se desviado dos aspectos fisiológicos às características psíquicas do comportamento humano". (CORRÊA, 1983)

Cerrando fileira e marcando posição, a Gazeta Médica da Bahia, já nesta época com uma tiragem de 5 mil exemplares, e utilizando os mesmos argumentos de Nina Rodrigues em editorial de 1906, sobre a Assistência médico legal aos alienados nos estados brasileiros, esta apoiava luta pela tutela dos alienados e pela autonomia em seu diagnóstico.

Não nos cansaremos de martelar relativamente à deficiência e anachronismo (sic) do Código Penal quanto aos artigos que se referam (sic) aos alienados delinqüentes. Note-se bem não se fala de "loucos" mas sim de "alienados"[...]. O Código penal é atrasado, não acompanhando a evolução do Direito Criminal [...]. No fundo da questão, a causa única do mal, o núcleo perturbador é a doutrina que orientou o código - o livre arbítrio - essa velharia já arruinada pela sciencia (sic). Enquanto esse mito não for de todo varrido do Código, a balbúrdia continuará como até hoje responsabilidade [...]. (GMB, 1913 apud SCHWARCS, 1993)

Ao desafiar o Código colocando-o como velho e ultrapassado, Nina Rodrigues buscava transformar a nova ciência da medicina legal como a única capaz de definir os rumos institucionais do cidadão tido como alienado, além de diminuir a importância dos pressupostos liberais.

Assim a Escola de Medicina da Bahia ia aos poucos impondo suas teorias, respaldada pela veiculação de artigos e editoriais, cujo objetivo maior era o de transformar as possíveis patologias mentais, não em um caso médico, passível de ser investigado como tal, mas sim em caso de polícia.

Embora não estejamos tratando da mídia televisiva, consideramos interessante lembrar a minissérie Tenda dos Milagres, inspirada na obra homônima de Jorge Amado, veiculada há alguns anos pela Rede Globo de Televisão, onde podemos assistir o embate travado entre o bedel Pedro Archanjo e o Professor Nilo Argolo, nitidamente representando Nina Rodrigues. O bedel, como negro e adepto das religiões afro-brasileiras, transforma-se no maior antagonista do cientista e passa a travar com este calorosas discussões questionando suas teorias, opondo ao discurso científico, eugenista e racial um autêntico discurso sobre a cultura negra e sua religiosidade.

Nina Rodrigues foi o maior difusor do discurso racial no tratamento das doenças psiquiátricas e da criminalidade patológica como um dispositivo de raças inferiores, admitindo assim a inferioridade da raça negra, como "um produto da marcha desigual do desenvolvimento filogenético da humanidade" (RODRIGUES, 1988). No entanto, este fazia ferrenha oposição às perseguições aos candomblés, pois, a seu ver, ao se perseguirem os negros por crimes cometidos na esfera comum, estariam colocando no mesmo patamar negros e brancos, coisa que este e seus seguidores rejeitavam terminantemente.

A cientifização do fenômeno criminológico inaugura uma febre de medições, de exercícios antropométricos, de invenções de instrumentos de aferição jamais vistos. Uma década após o surgimento de O Homem Criminoso, aparece um novo universo de publicações e a realização de vários congressos.

A medicina legal, com toda sua bagagem instrumental de aferição e classificação, através da craniometria, da antropometria, da frenologia ofereceu a mediação 
técnica e empírica que outras áreas mais gerais do saber médico não possuíam em seu tempo (MAIO, 1995).

Segundo Schwarcs, (1993), os casos de degeneração racial podiam finalmente ser expostos e estudados através desta ciência "embriaguez, alienação, loucura, epilepsia, violência ou amoralidade" passavam a corroborar os modelos insistentemente citados como prova da ineficácia de um cruzamento, dando um alerta para a "impossibilidade de uma hereditariedade mista" cujo resultado seria o "enfraquecimento da raça".

Através dos instrumentos fornecidos pelas novas ciências que surgiam os estudos sobre alienação vão recrusceder em sua crítica acerca da igualdade dos homens. As críticas diziam respeito à existência inequívoca de provas que demonstravam diferenças entre as raças e o malefício advindo da mistura entre grupos distintos - a miscigenação.

Em suma, sob o discurso psiquiátrico pairam inúmeras inserções argumentativas que remetem discutir o negro e sua cultura por meio de categorias preconceituosas, mascaradas de científicas, para sustentar interesses e visões unilaterais da realidade.

As incoerências e constatações do preconceito no discurso psiquiátrico, que ganharam força de ação até hoje, podem ser encontradas já a partir de 1886, em estudos realizados por Franco da Rocha, o qual aponta estatísticas que enaltecem as diferenças durante as manifestações de "doenças mentais" que serão tratadas tendenciosamente atreladas ao que concerne aos brancos e ao que concerne aos negros.

Essa referência será também retomada por Nina Rodrigues, o qual, em 1891, em nosso entendimento, propusera mais um conjunto de signos, que juntos tinham como objetivo descaracterizar aquilo que entendemos por cultura negra.

Nina Rodrigues será um dos estudiosos da psiquiatria que fomentará o discurso psiquiátrico, em que negros são vistos como "altamente sugestionáveis e, em contrapartida aos brancos altamente racionais", o que preconiza, aparentemente, a tendência de encararmos o negro como detentor de um comportamento paranóico que raramente ocorre naqueles que sejam brancos, ou seja: Nina Rodrigues ressalta que "nesta perspectiva a paranóia seria uma modalidade de enfermidade muito desenvolvida entre os negros, exatamente porque a sugestão estaria na base das manifestações histéricas e paranóicas." (RODRIGUES, 1988).

Essa afirmação vai sustentar ainda a idéia de existirem, desvios tipicamente de negros e que isto tinha ligação direta também com uma postura criminosa. O poligenista e relativista Nina Rodrigues é bastante explícito na sua defesa de que os negros não poderiam ser tratados em pé de igualdade com os brancos, já que seriam inferiores biologicamente e, portanto, incapazes de se conduzirem como cidadãos em seus plenos direitos. No contexto científico do final do Século XIX, o saber médico-legal localizará nos corpos a fonte das desigualdades sociais e terá como meta a defesa da criação de padrões diferenciados de acesso à cidadania. Em especial, no Brasil, este debate envolveu o tema do futuro da nação pós-abolicionista e republicana, onde a incorporação de amplos segmentos da sociedade ao mundo do trabalho e da política, sob novas bases, tornou-se questão central (CORRÊA, 1982; SCHWARCS, 1993; MAIO, 1995).

Se no século passado a luta dos médicos se desenvolveu no sentido de monopolizar o exercício da medicina contra os leigos e os charlatães, a partir da passagem do século uma nova disputa se associará à primeira. Desta vez, a competição se refletirá no interior da própria categoria médica, a partir da era das especialidades.

Desde o final do Século XIX, os médicos-legistas procuraram questionar os fundamentos dos clínicos gerais em matéria de medicina legal. Esta crítica apareceria com maior evidência na cotidiana tarefa de comprovar a fragilidade das perícias realizadas por clínicos. É nesta luta com os médicos clínicos que se constituirá o campo autônomo da medicina legal, campo este que será configurado definitivamente nas três primeiras décadas deste século. Desse modo, a criação de uma associação e de uma revista não-oficiais voltadas para as questões médico-legais deram maior legitimidade à especialização (MAIO, 1995; ODA, 2001)

Nina Rodrigues preocupou-se em reivindicar para estas disciplinas- a psiquiatria e a medicina legal - a prerrogativa de explicar cientificamente o comportamento humano e de, em conseqüência, ditar as regras para a avaliação de indivíduos cujas atitudes fossem consideradas mórbidas, decidir quanto à sua imputabilidade penal e, principalmente, sugerir meios preventivos para evitar a loucura e o crime.

Nina Rodrigues acreditava que as três raças que reconhecia como fundadoras da nação (negros, índios e brancos) transmitiriam "aos produtos de seus cruzamentos caracteres patológicos diferenciais de valor" (RODRIGUES, 1988), e que a correta diferenciação das raças seria muito importante para a prática médica, nas doenças físicas como nas mentais. Para ele, a inferioridade racial dos negros e indígenas, com relação ao branco, era indiscutível; assim sendo, a miscigenação entre raças em diferentes patamares evolutivos resultaria, fatalmente, em indivíduos desequilibrados, degenerados, híbridos do ponto de vista físico, intelectual e nas suas 
manifestações comportamentais. A seu ver, um leve verniz de civilização poderia recobrir as populações mestiças, como os sertanejos, mas certas condições sociais fariam eclodir o lado bárbaro e selvagem destes, mal refreado por regras que não eram as suas, incompatíveis com o seu suposto nível mental. (ODA, 2001).

\section{CONSIDERAÇÕES FINAIS}

O discurso psiquiátrico do final do Século XIX e do início do Século XX, apoiado em pressupostos científicos europeus, acabava por colocar em destaque a figura do negro. Colocados à mercê de estudiosos ciosos de demonstrarem o seu conhecimento recém adquirido nas modernas modalidades médicas, negros e índios irão pontuar constantemente os exemplos acionados quando da necessidade de se falar de criminalidade e degenerescência.

Desde a publicação de seu primeiro livro - As raças humanas e a responsabilidade penal no Brasil, de 1894 Nina Rodrigues, o principal expoente da Escola de Medicina da Bahia e fiel propagador das discussões travadas em seu interior, acena com teorias que, além de falarem da suposta inferioridade racial do povo negro, ainda atentavam para a sua predisposição criminosa. Segundo ele:

(...) A sobrevivência criminal é, ao contrário, um caso especial de criminalidade, aquele que se poderia chamar de criminalidade étnica, resultante da coexistência, numa mesma sociedade, de povos ou de raças em fases diversas de evolução moral e jurídica, de sorte que aquilo que ainda não é imoral nem antijurídico para uns réus já deve sê-lo para outros. Desde 1894 insisto no contingente que prestam à criminalidade brasileira muitos atos antijurídicos das populações inferiores, negra e vermelha, os quais contrários à ordem social estabelecida no país pelos brancos, são todavia, perfeitamente lícitos, morais e jurídicos, considerados do ponto de vista a que pertencem os que praticam. A contribuição dos negros a esta espécie de crimes das mais elevadas. Na sua forma, esses atos procedem, uns do estádio de sua evolução jurídica, procedem outros de suas crenças religiosas. (RODRIGUES, 1988).

Permeando então um campo de oposições e até mesmo de aniquilação do negro em relação ao branco, a psiquiatria brasileira e a medicina legal vão interpretar todo um conjunto de traços que compõem a cultura negra como sendo inferior à praticada pelos brancos e, neste momento, praticamente se consolidará todo um pensamento equivocado a respeito dos cultos afro-brasileiros e de seus praticantes.

Portanto, a visão que foi concebida e que, invariavelmente, ainda se manifesta atualmente sobre os cultos afro-brasileiros, deve-se em grande parte a associar tais manifestações como casos de loucura ou a, como o próprio Nina Rodrigues referiuse, como "um estado de sonambulismo provocado que se basearia na sugestionabilidade da raça negra" (RODRIGUES, 1988).

É somente entre os anos 40 e 50 que os estudos psiquiátricos começam a rever seus conceitos, influenciados pelo deslocamento da antropologia física para um posicionamento mais próximo à cultura; vão se concentrar em perceber as manifestações dos cultos afro-brasileiros como pertencentes a uma determinada manifestação da cultura, neste caso a negra. (MANDARINO, 2007)

Com este deslocamento, os cultos afro-brasileiros vão, aos poucos, sendo percebidos como "formas de cura e de adaptação" (RODRIGUES, 1988). Contudo, ainda permeavam em tais estudos o ranço do passado, usando, toda vez que possível, distinções que tinham como objetivo relativizar o potencial dos negros em relação aos brancos. (MANDARINO, 2007)

Birman (1978) destaca que nos anos finais do Século XIX "não só a figura do negro foi definida como sendo inferior à do branco na sua estrutura psicofísica - sugestão versus razão versus psiquismo, barbárie versus civilização como também as modalidades de existência cultural foram esvaziadas e reduzidas a formas de enfermidade" (BIRMAN, 1978 apud MANDARINO, 2007).

Este quadro, além do mais, carrega consigo uma das formas de exercer o controle social. Afinal ficam evidentes as condutas consideradas certas/normais das consideradas erradas/anormais e que vão passar a condicionar os comportamentos em sociedade como uma plena demonstração de um "enquadramento social" às novas ordens estabelecidas.

Nesta perspectiva, acreditamos que a loucura e os rótulos de macumbeiro, louco e criminoso que incidem ainda hoje sobre os negros e, em especial, sobre os praticantes das religiões afro-brasileiras, encontram-se vinculados ao conjunto de idéias recorrentes no senso comum e, no cotidiano, o que reforça os estereótipos negativos calcados nas teses evolucionistas sobre raça e sobre os cultos de possessão.

No quadro em que se explana a pluralidade da sociedade brasileira, além da discriminação que recai sobre tudo ou todos que são considerados negros ou afro, o rótulo 
de macumbeiro supõe ainda outra dimensão: aquela estabelecida pela Escola de Patologia Social que associa certas práticas rituais, como possessão, à loucura e a criminalidade. Outras doenças também foram atribuídas aos negros e mestiços, assim como atributos morais e comportamentais, o que contribuiu fortemente para o enquadramento dessas populações e de suas manifestações culturais e religiosas como produzidas por gente de segunda categoria, segundo Nina Rodrigues.

As representações acerca da loucura e da criminalidade no contexto negro religioso ou da cultura negra podem ser entendidas como construções que atendem às necessidades impostas pelo contexto social. Teixeira (1994) realça a importância das representações na vida cotidiana e o seu caráter social:

perante o mundo dos objetos, das pessoas, de acontecimentos e de idéias, nós não estamos apenas equipados com automatismos, da mesma forma que não estamos isolados no vazio social: o mundo é partilhado com os outros, e neles, nos apoiamos - às vezes, solidariamente, outras vezes conflituosamente para compreendê-lo, para gerenciá-lo ou para afrontá-lo (TEIXEIRA, 1994)

Este fato pode ser detectado através da composição do discurso psiquiátrico adotado no Brasil, na tentativa de explicar os desvios de comportamento de determinados membros ou grupos sociais, criando uma espécie de agenciamento da nova ordem social.

Em artigo publicado, em 1978, Birman destaca que o discurso psiquiátrico ocupa uma posição estratégica no processo de invalidação social e política da figura do negro nos primórdios do Estado Republicano, funcionando como uma das instâncias institucionais onde se empreendeu a legitimação de sua inferioridade social face à figura do negro.

Este discurso perdurou durante todo o processo de estudos e aplicação de técnicas psiquiátricas, no Brasil, na tentativa de evidenciar, através de meios científicos, os porquês dos desvios de comportamento praticados em sociedade, a qual os entenderia basicamente com o auxílio de suas tipificações, ou seja - a raça - difundida pela antropologia física - e a étnica - difundida pela antropologia social.

\section{Referências}

BIRMAN, J. A psiquiatria como discurso da moralidade. Rio de Janeiro: Graal, 1978.

CORRÊA, M. As ilusões da liberdade: a escola de Nina Rodrigues e a Antropologia no Brasil. São Paulo: Edusp, 1983.

GALTON, F. Herencia y Eugenia. Madrid: Alianza Editorial, 1979.

GOULD. J. S. A falsa medida do homem. São Paulo: Martins Fontes, 1991

JACOBINA, R.R.; GELMAN, E.A. Juliano Moreira e a Gazeta Médica da Bahia. História, Ciências, Saúde-Manguinhos, v. 15, n.4, p. 1077-1097, 2008.

MACIEL, M. S. A eugenia no Brasil. Anos 90: Revista do Programa de Pós-Graduação em História UFRG, n.11, p.121130, 1999.

MAIO, M.C. A medicina de Nina Rodrigues: análise de uma trajetória científica. Cadernos de Saúde Pública, v.11, n.2, p.226-237, 1995.

MANDARINO, A.C.S. (Não) deu na primeira página: macumba loucura e criminalidade. São Cristovão: Editora UFS, 2007.

ODA, A.M.G.R. A teoria da degenerescência na fundação da psiquiatria brasileira: contraposição entre Raimundo Nina Rodrigues e Juliano Moreira. Psychiatry on Line Brazil, n.6, p.1-14, 2001. Disponível em: www.polbr.med.br/arquivo/ wal1201.htm. Acesso em: 2 out. 2005.

RODRIGUES, R.N. Os africanos no Brasil. Brasília: Editora UNB, 1988.

SCHWARCZ, L.M. O espetáculo das raças. São Paulo: Companhia das Letras, 1993.

TEIXEIRA, M.L.L. Encruzilhada do ser: representações da (Lou) cura em terreiros de candomblé. Tese (Doutorado) - Faculdade de Filosofia, Letras e Ciências Humanas, Universidade de São Paulo, São Paulo, 1994. 